\title{
A novel detection method for Escherichia coli 0157 by Peptide Nucleic Acid array
}

\author{
Ki-Eun Lee ${ }^{1}$, Woo-Seog Jeong ${ }^{1}$, Seong-In Lim ${ }^{1}$, Se-Ryun Kim ${ }^{3}$, Yong-Kuk Kwon ${ }^{1}$, Jin-San Moon ${ }^{1}$, \\ Soo-Yeon Cho ${ }^{2}$, Jae-Young Song ${ }^{1}$, Dong-Jun An ${ }^{1, *}$
}

${ }^{1}$ Animal, Plant Quarantine Agency, Anyang, Gyeonggido 430-824, South Korea

${ }^{2}$ Animal, Plant Quarantine Agency, Seoul regional office, Seoul 157-843, South Korea

${ }^{3}$ Panagene Incorporated, Daejon 305-510, South Korea

\section{Email address:}

andj67@korea.kr (D.-J.An)

\section{To cite this article:}

Ki-Eun Lee, Woo-Seog Jeong, Seong-In Lim, Se-Ryun Kim, Yong-Kuk Kwon, Jin-San Moon, Soo-Yeon Cho, Jae-Young Song, DongJun An. A Novel Detection Method for Escherichia Coli O157 by Peptide Nucleic Acid Array. International Journal of Nutrition and Food Sciences. Vol. 3, No. 2, 2014, pp. 14-18. doi: 10.11648/j.ijnfs.20140302.11

\begin{abstract}
E. coli $\mathrm{O} 157$ is responsible for a number of human infections through the consumption of foods of animal origin, particularly those originating from cattle. Food poisoning by Escherichia coli O157 causes diarrhea, bloody stools and abdominal pain in humans, and may lead to severe kidney failure or brain injury. For these reasons, E. coli O157 has been the subject of increasingly stringent international regulations. A novel peptide nucleic acid (PNA) array was developed to identify $E$. coli $\mathrm{O} 157$ quickly and accurately. This PNA array exhibited high specificity, significantly detecting E. coli $\mathrm{O} 157$ strains without cross-reacting with other bacterial strains. The detection limit of the E. coli O157 PNA array was $100 \mathrm{CFU} / \mathrm{ml}$. The E. coli O157 PNA array is indeed a better option for early detection and accurate diagnosis of the causative agent of a food-borne disease outbreak, which is crucial in planning and implementing strategic measures to prevent and control widespread outbreaks.
\end{abstract}

Keywords: Escherichia coli O157, Peptide Nucleic Acid Array, Food Poisoning

\section{Introduction}

Food poisoning with Escherichia coli 0157 was first reported in 1982 [19]. From 1982 to 2002, a total of 8,598 cases of E. coli $\mathrm{O} 157$ infection were detected in the United States [17]. In England and Wales, 3,429 isolations of verocytotoxin-producing $E$. coli $\mathrm{O} 157$ from human sources were confirmed from 1995 to 1998 [26]. Infection with $E$. coli $\mathrm{O} 157$ is associated with the consumption of raw or undercooked meat and other foods or water contaminated with animal feces [6, 27]. Symptoms of E. coli 0157 infection may be life-threatening, and include abdominal cramps, watery diarrhea, fever, vomiting, and hemorrhagic colitis [8].

Current schemes for the detection and identification of $E$. coli $\mathrm{O} 157$ rely on a combination of culture methods and biochemical and serological tests. However, established culture methods and biochemical tests for E. coli $\mathrm{O} 157$ identification are laborious and time consuming [10]. Moreover, serotyping requires skilled workers to carry out the tests $[6,25]$. With recent advances in genetic technologies, molecular-based tests using PCR $[5,10,12]$ and DNA microarrays have led to remarkable improvements in methods for the direct detection of $E$. coli $\mathrm{O} 157$ [16, 23]. The E. coli O157 O side chain contains four different sugars, including GDP-perosamine, which form the $\mathrm{O}$ side chain of the lipopolysaccharide (LPS) [20]. GDP-perosamine synthetase (per) is specific for $E$. coli O157, so it has been utilized for the identification of this bacterial strain [16].

Peptide nucleic acid (PNA), a novel oligonucleotide in which the sugar phosphate backbone is replaced by a pseudo-peptide skeleton, is notable for its exceptional biological and chemical stability as a nucleic acid analogue $[13,14]$. PNA has been used to develop assays with improved detection limits, detection of sequence variations, and sensitivity [3, 15]. Moreover, PNA-DNA hybridization is more specific than the corresponding DNA-DNA duplex $[2,18,24]$. Due to these advantages, PNA has been widely used as a tool for molecular-based detection [1, 4, 9]. In the present study, we developed a PNA array-based method for the specific detection of E. coli $\mathrm{O} 157$ and compared its 
detection limit and specificity with those of traditional culture-based methods.

\section{Materials and Methods}

\subsection{Bacterial Strains and Serotyping}

The bacterial strains containing E. coli O157:H7 are shown in Table 1. The four substrains of E. coli O157:H7 used were E. coli O157:H7 ATCC 43894 (Manassas, VA, USA), E. coli O157:H7 ATCC 43895 (Manassas, VA,
USA), E. coli O157:H7 C163 (E.coli Reference center, PA, USA), and E. coli O157:H7 WSU 3110 (Washington State University, WA, USA). The other strains (Korea Veterinary Culture Collection, Animal, Plant Quarantine Agency, Anyang, South Korea) listed in Table 1 were used as controls. Serological analysis of E. coli was performed by slide and tube agglutination with $51 \mathrm{O}$ and $22 \mathrm{H}$ antisera, according to the manufacturer's instructions (Denka Seiken, Tokyo, Japan).

Table 1. Evaluation of the specificity of the E. coli O157 PNA array using pure culture bacteria

\begin{tabular}{|c|c|c|c|}
\hline Bacteria & Strain no. & Intensity value & PNA results* \\
\hline E. coli $\mathrm{O} 157: \mathrm{H} 7$ & ATCC 43894 & $14203.3 \pm 49.7$ & + \\
\hline E. coli $\mathrm{O} 157: \mathrm{H} 7$ & ATCC 43895 & $18894.7 \pm 19.5$ & + \\
\hline E. coli $\mathrm{O} 157: \mathrm{H} 7$ & C 163 & $19726.7 \pm 19.7$ & + \\
\hline E. coli $\mathrm{O} 157: \mathrm{H} 7$ & WSU 3110 & $23151.7 \pm 27.9$ & + \\
\hline E. coli $\mathrm{O} 6: \mathrm{H}-$ & KVCC-BA0000515 & $-34.0 \pm 9.0$ & - \\
\hline E. coli $\mathrm{O} 8: \mathrm{H} 19$ & KVCC-BA0000516 & $-34.8 \pm 7.3$ & - \\
\hline E. coli $\mathrm{O} 15: \mathrm{H} 25$ & KVCC-BA0001440 & $-14.3 \pm 7.9$ & - \\
\hline E. coli $\mathrm{O} 20: \mathrm{H}-$ & KVCC-BA0000520 & $-22.8 \pm 7.9$ & - \\
\hline E. coli $\mathrm{O} 26: \mathrm{H}-* *$ & & $-4.3 \pm 7.5$ & - \\
\hline E. coli $\mathrm{O} 86: \mathrm{H} 25$ & KVCC-BA0002388 & $110.2 \pm 10.4$ & - \\
\hline E. coli $\mathrm{O} 111: \mathrm{H}-$ & KVCC-BA0002395 & $1.3 \pm 10.3$ & - \\
\hline E. coli $\mathrm{O} 112: \mathrm{H} 8$ & KVCC-BA0002396 & $-5.8 \pm 8.9$ & - \\
\hline E. coli $\mathrm{O} 128: \mathrm{H} 2$ & KVCC-BA0002407 & $-26.2 \pm 7.1$ & - \\
\hline E. coli $\mathrm{O} 139: \mathrm{H} 1$ & KVCC-BA0000533 & $411.0 \pm 16.3$ & - \\
\hline E. coli $\mathrm{O} 141: \mathrm{H} 4$ & KVCC-BA0000534 & $12.8 \pm 7.2$ & - \\
\hline E. coli $\mathrm{O} 147: \mathrm{H} 19$ & KVCC-BA0002414 & $1.5 \pm 9.4$ & - \\
\hline E. coli $\mathrm{O} 148: \mathrm{H} 28$ & KVCC-BA0002415 & $-35.5 \pm 7.9$ & - \\
\hline E. coli $\mathrm{O} 149: \mathrm{H} 10$ & KVCC-BA0002416 & $-32.2 \pm 4.8$ & - \\
\hline E. coli $\mathrm{O} 153: \mathrm{H} 7$ & KVCC-BA0002417 & $446.5 \pm 4.1$ & - \\
\hline E. coli $\mathrm{O} 159: \mathrm{H} 20$ & KVCC-BA0002419 & $-5.2 \pm 15.8$ & - \\
\hline Campylobacter lari & KVCC-BA0902581 & $-80.5 \pm 7.7$ & - \\
\hline Campylobacter jejuni & KVCC-BA0902577 & $-81.5 \pm 4.2$ & - \\
\hline Clostridium perfringens & KVCC-BA0000578 & $-25.7 \pm 2.5$ & - \\
\hline Clostridium perfringens & KVCC-BA1100001 & $-92.5 \pm 9.1$ & - \\
\hline Enterococcus faecalis & KVCC-BA0000404 & $7.2 \pm 3.5$ & - \\
\hline Enterococcus faecium & KVCC-BA0000412 & $-3.8 \pm 16.3$ & - \\
\hline Enterococcus hirae & KVCC-BA0700653 & $4.5 \pm 7.9$ & - \\
\hline Listeria grayi & KVCC-BA0000577 & $-14.5 \pm 8.1$ & - \\
\hline Listeria innocua & KVCC-BA0000576 & $-0.7 \pm 5.7$ & - \\
\hline Listeria monocytogenes & KVCC-BA0000575 & $4.7 \pm 10.4$ & - \\
\hline Pasteurella multocida & KVCC-BA0000513 & $15.2 \pm 7.8$ & - \\
\hline Salmonella berta & KVCC-BA0000581 & $-36.0 \pm 5.3$ & - \\
\hline Salmonella derby & KVCC-BA0000582 & $-20.3 \pm 4.4$ & - \\
\hline Salmonella dublin & KVCC-BA0000584 & $-22.7 \pm 7.2$ & - \\
\hline Salmonella enteritidis & KVCC-BA0400601 & $-90.7 \pm 6.0$ & - \\
\hline Salmonella gallinarum & KVCC-BA0700722 & $-5.8 \pm 4.6$ & - \\
\hline Salmonella glustrup & KVCC-BA0000583 & $30.3 \pm 4.6$ & - \\
\hline Salmonella illinois & KVCC-BA0000585 & $-20.3 \pm 2.6$ & - \\
\hline Salmonella mиenster & KVCC-BA0000586 & $5.8 \pm 6.2$ & - \\
\hline Salmonella oranienberg & KVCC-BA0000587 & $28.2 \pm 5.1$ & - \\
\hline Salmonella paratyphi $B$ & KVCC-BA0000588 & $-10.2 \pm 8.4$ & - \\
\hline Salmonella senftenberg & KVCC-BA0000590 & $-9.7 \pm 4.0$ & - \\
\hline Salmonella tallahassee & KVCC-BA0000589 & $-17.7 \pm 8.7$ & - \\
\hline Salmonella tennessee & KVCC-BA0000592 & $-33.0 \pm 7.8$ & - \\
\hline Salmonella typhimurium & KVCC-BA0000591 & $-24.5 \pm 7.4$ & - \\
\hline Salmonella uganda & KVCC-BA0000596 & $-25.8 \pm 5.5$ & - \\
\hline
\end{tabular}




\begin{tabular}{lllc}
\hline Bacteria & Strain no. & Intensity value & PNA results* \\
\hline Salmonella virchow & KVCC-BA0000595 & $-28.2 \pm 5.1$ & - \\
Salmonella typhimurium & KVCC-BA0400600 & $-102.2 \pm 8.2$ & - \\
Staphylococcus epidermidis & KVCC-BA0001452 & $6.5 \pm 16.3$ & - \\
Staphylococcus aureus & KVCC-BA0000098 & $-4.2 \pm 4.9$ & - \\
Streptococcus dysgalactiae & KVCC-BA0001419 & $2.3 \pm 3.8$ & - \\
Streptococcus equi & KVCC-BA0201420 & $1.7 \pm 3.5$ & - \\
Streptococcus iniae & KVCC-BA0000100 & $6.2 \pm 4.9$ & - \\
Streptococcus parauberis & KVCC-BA0000187 & $-0.8 \pm 7.5$ & - \\
Streptococcus suis & KVCC-BA0000579 & $-3.2 \pm 4.9$ & - \\
Vibrio parahaemolyticus & KVCC-BA0001825 & $-5.0 \pm 7.1$ & - \\
Yersinia enterocolitica & KVCC-BA0000716 & $-14.5 \pm 0.7$ & - \\
\hline
\end{tabular}

* Results of the PNA array were defined as negative $(<3,000)$ or positive $(>3,000)$ on the basis of the intensity value. ** E. coli $\mathrm{O} 26$ : $\mathrm{H}-$ was kindly provided by Dr. Min-soo Kang of Animal, Plant Quarantine Agency.

\subsection{Assay of CFU and Preparation of E. coli O157 DNA}

Analysis of colony forming units (CFU) was based on varying lengths of incubation time $(0,1,3$, and $5 \mathrm{~h})$ of $E$. coli O157 culture that was inoculated into modified Escherichia coli (mEC) broth. The culture broth was then inoculated into MacConkey agar and incubated for $24 \mathrm{~h}$ at $37{ }^{\circ} \mathrm{C}$. After incubation, the colonies were counted, and then, for the PNA assay, bacterial DNA was extracted using a genomic DNA extraction kit (iNtRon Biotechnology Inc., Seongnam, South Korea), and stored at $-20{ }^{\circ} \mathrm{C}$ until use.

\subsection{Design and Synthesis of PNA Probe}

The PNA probe (NH2-linkerCGATGCCAATGTACTCGG) was designed on the basis of the E. coli O157-specific per region. The spotting mixture buffer (Panagene, Daejeon, South Korea), including the probe, was printed onto epoxy-coated slides with a 2470 arrayer (Aushon Biosystems, Billerica, MA, USA). The printed slide was blocked with succinic anhydride. Nested PCR for the detection of E. coli $\mathrm{O} 157$ using the PNA array was performed twice with a biotin-conjugated primer set (forward, 5'-TTCACACTTATTGGATGGTCTCA-3', and reverse, 5'-TCGATAGGCTGGGGAAACT-3'). The first reaction mixture $(25 \mu \mathrm{l})$ contained $1 \mathrm{U}$ of $\mathrm{Taq}$ DNA polymerase (Solgent, Daejeon, South Korea) and PCR buffer with $1.5 \mathrm{mM} \mathrm{MgCl} 2,150 \mu \mathrm{M}$ deoxynucleoside triphosphate mixture, and $0.08 \mu \mathrm{M}$ of each specific primer. The second reaction mixture was the same as the first PCR mixture, except that $0.04 \mu \mathrm{M}$ forward primer and $2 \mu \mathrm{M}$ reverse primer were used. The first PCR program was 5 min at $95^{\circ} \mathrm{C}, 15$ cycles of $30 \mathrm{sec}$ at $95{ }^{\circ} \mathrm{C}, 30 \mathrm{sec}$ at $50{ }^{\circ} \mathrm{C}$, and $60 \mathrm{sec}$ at $72{ }^{\circ} \mathrm{C}$, and final incubation of $10 \mathrm{~min}$ at $72^{\circ} \mathrm{C}$ The second PCR program consisted of 45 cycles of the same temperature and time conditions.

\subsection{Hybridization and Scanning of PNA Array}

Five microliters of biotin-labeled target DNA were mixed with $70 \mu \mathrm{l}$ of PNA hybridization buffer (Panagene, Daejeon, South Korea) containing Cy5-streptavidin (Amersham Pharmacia, Buckinghamshire, UK) and applied to the PNA array. The PNA array was incubated for $2 \mathrm{~h}$ at
$40{ }^{\circ} \mathrm{C}$. After hybridization, PNA array images were taken by a nonconfocal fluorescent scanner (Axon Instruments, Union City, CA, USA) with a typical laser power of $100 \%$ and photomultiplier tube gain of 700. Scanning to detect Cy5 was performed with GenPro Pix 6.0 software (Axon Instruments, Union City, CA, USA), at a wavelength of 635 nm. Fluorescence signal intensities represent the hybridization signals of the PNA probe-target duplexes.

\section{Results and Discussion}

\subsection{Efficacy of the PNA Probe for E. coli 0157}

The performance of the PNA array as a detection assay for E. coli $\mathrm{O} 157$ is shown in Table 1. A positive signal for the PNA array was defined as an intensity value of $\geq 3,000$. Among the 57 strains, only four $E$. coli O157 strains (ATCC 43894, ATCC 43895, C163, and WSU 3110) gave positive results, with intensity values from $>14,203.0 \pm 49.7$ to $23,151.7 \pm 27.9$. The remaining 53 strains gave negative signals, with intensity values from $-102.2 \pm 8.2$ to $446.5 \pm 4.1$ (Table 1). The E. coli O157-specific probes hybridized specifically to their corresponding targets and did not crosshybridize with other strains.

\subsection{CFU Change with Incubation Time and Detection Limit of the PNA Array}

The CFU and PNA array results for E. coli $\mathrm{O} 157$ with incubation times of $0,1,3$, and $5 \mathrm{~h}$ are shown in Fig. 1 and Fig. 2. Four E. coli O157 strains were inoculated into the mEC broth. CFU was calculated using the culture and colony counting method at different incubation time intervals. The CFU values for all four $E$. coli $\mathrm{O} 157$ strains were $10^{2}$ after $1 \mathrm{~h}, 10^{3}$ after $3 \mathrm{~h}$, and $10^{5}$ after $5 \mathrm{~h}$ of incubation. After $1 \mathrm{~h}$ of incubation, the PNA intensity values of the four E. coli O157 substrains (ATCC 43894, ATCC 43895, C163, and WSU 3110) were 3,052.2 \pm 5.1 , $3,750.0 \pm 5.0,3,543.8 \pm 8.6$, and 7,415.0 \pm 7.2 , respectively. Thus, all four of the substrains gave positive signals. The detection limit of the E. coli O157 PNA array was 100 $\mathrm{CFU} / \mathrm{ml}$. After $5 \mathrm{~h}$ of incubation, the PNA intensity values of the four substrains were $14,203.3 \pm 49.7,18,894.7 \pm 19.5$, 


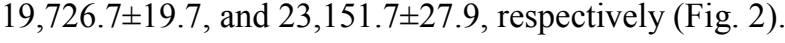

\begin{tabular}{|c|c|c|c|c|}
\hline & \multicolumn{4}{|c|}{ Incubation time } \\
\hline & $0 \mathrm{hr}$ & $1 \mathrm{hr}$ & $3 \mathrm{hr}$ & $5 \mathrm{hr}$ \\
\hline E. coli 0157 ATCC 43894 & & & 0 & 0 \\
\hline E. coli 0157 ATCC 43895 & & & 0 & 0 \\
\hline E. coli 0157 C 163 & & 0 & e & 0 \\
\hline E. coli 0157 WSU 3110 & & 0 & 0 & 0 \\
\hline
\end{tabular}

Figure 1. Scanned images of the peptide nucleic acid (PNA) microarray, with $\mathrm{E}$. coli $\mathrm{O} 157$ at different incubation time intervals.

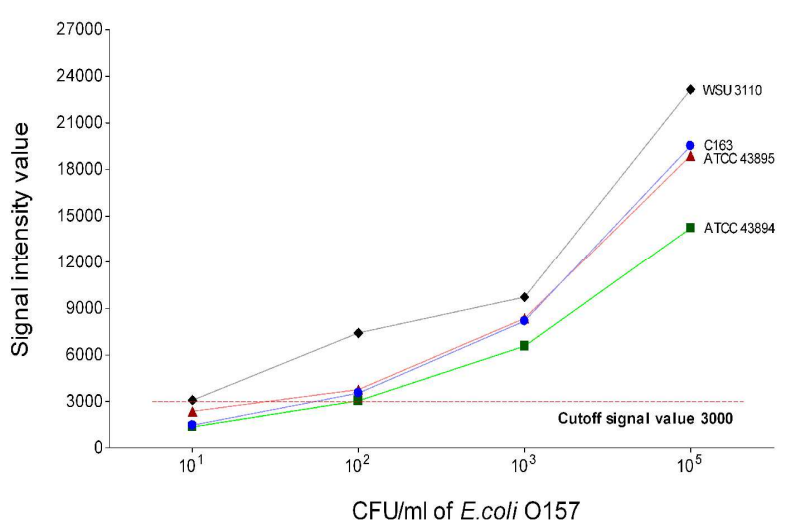

-, E. coli $\mathrm{O} 157$ ATCC 43894; $\boldsymbol{\Delta}$, E. coli $\mathrm{O} 157$ ATCC 43895; •, E. coli O157 C163; • E. coli O157 WSU 3110.

Figure 2. Colony forming units (CFU) and sensitivity of four E. coli O157 strains detected with the peptide nucleic acid (PNA) microarray.

Recent advances in nucleic acid recognition, including the introduction of PNA, provide exciting opportunities for DNA biosensors. PNA has several advantages as a probe molecule, such as superior hybridization characteristics, detection of single-base mismatches, and improved chemical and enzymatic stability compared with nucleic acids. In addition, its unique molecular structure enables new modes of label-free detection, contributing to the establishment of rapid, stable, and reliable analytical processes. PNA sensing can be used to detect pathogens of interest with high stability and increased affinity for target sequences [22]. Accordingly, PNA probes have been applied to fluorescence in situ hybridization and single nucleotide polymorphism detection [11, 21]. Using current culture methods, detection of E. coli $\mathrm{O} 157$ would take about 7 days, whereas identification by the PNA array required only 1-2 days. To improve the culture methods, molecular-detection methods (PCR, enzyme immunoassay, rapid kit methods) have been developed. However, these methods have low specificity and high detection limits. The pathogenicity of $E$. coli $\mathrm{O} 157$ is associated with numerous virulence factors, including verotoxin 1 (VT1) and verotoxin 2 (VT2). Although VT1 and VT2 detection methods have been used to detect E. coli $\mathrm{O} 157$ by PCR, this diagnostic method is not accurate because some E. coli O157 strains do not produce verotoxin. We detected VT1 in E. coli strains O157:H7 ATCC 43894, ATCC 43895 and C163, and VT2 in E. coli strains O157:H7 ATCC 43894, ATCC 43895 and WSU 3110 (data not shown). An enzyme immunoassay for E. coli $\mathrm{O} 157$ has been developed as a sandwich-type assay with polyclonal antibodies to the bacteria; however, this method can only detect $E$. coli $\mathrm{O} 157$ at concentrations $\geq 1.3 \times 10^{5} \mathrm{CFU} / \mathrm{ml}$ [7]. Recently, Realtime PCR methods have been used to detect low density of E. coli $\mathrm{O} 157$, but this diagnostic method can not be used on large-scale because of the reagent and instrumentation cost. Taken together, these results show that the PNA array is an effective method for detecting E. coli O157.

\section{Conclusion}

We have developed a novel PNA-based microarray for detecting E. coli O157. This method allows rapid and accurate high-throughput screening of bacteria that cause food-poisoning, from a large number of food animal samples. The E. coli O157 PNA array is indeed a better option for early detection and accurate diagnosis of the causative agent of a food-borne disease outbreak, which is crucial in planning and implementing strategic measures to prevent and control widespread outbreaks. Furthermore, this PNA array could also be an effective research and diagnostic protocol to gather epidemiological data useful for policy formulation in establishing food safety and ensuring national food security.

\section{References}

[1] Beau-Faller, M., Legrain, M., Voegeli, A.C., Guerin, E., Lavaux, T., Ruppert, A.M., Neuvile, A., Massard, G., Wihlm, J.M., Quoix, E., Oudet, P., Gaub, M.P., 2009. Detection of $K$-Ras mutations in tumour samples of patients with nonsmall cell lung cancer using PNA-mediated PCR clamping. Br. J. Cancer. 100, 985-992.

[2] Brandt, O., Feldner, J., Stephan, A., Schroder, M., Schnolzer, M., Arlinghaus, H.F., Hoheisel, J.D., Jacob, A., 2003. PNA microarrays for hybridization of unlabelled DNA samples. Nucleic. Acids. Res. 31, e119.

[3] Brandt, O., Hoheisel, J.D., 2004. Peptide nucleic acids on microarrays and other biosensors. Trends. Biotechnol. 22, 617-622.

[4] Choi, J.J., Kim, C., Park, H., 2009. Peptide nucleic acidbased array for detecting and genotyping human papillomaviruses. J. Clin. Microbiol. 47, 1785-1790.

[5] Gannon, V.P.J., D'souza, S., Graham, T., King, R.K., Rahn, K., Read, S., 1997. Use of the flagellar H7 gene as a target in multiplex PCR assays and improved specificity in identification of enterohemorrhagic Esherichia coli strains. J. Clin. Microbiol. 35, 656-662. 
[6] Jo, M.Y., Kim, J.H., Lim, J.H., Kang, M.Y., Koh, H.B., Park, Y.H., Yoon, D.Y., Chae, J.S., Eo, S.K., Lee, J.H., 2004. Prevalence and characteristics of Escherichia coli $\mathrm{O} 157$ from major food animals in Korea. Int. J. Food. Microbiol. 95, 41-49.

[7] Jung, B.Y., Jung, S.C., Cho, D.H., Kim, J.Y., Park, Y.H., Shin, S.J., Kim, S.S., Kim, B.H., 1998. Development of an enzyme immunoassay for detection of Escherichia coli O157 in meat. Korean. J. Vet. Res. 38, 745-750.

[8] Karmali, M.A., 1989. Infection by verocytotoxin-producing Escherichia coli. Clin. Microbiol. Rev. 2, 15-38.

[9] Kempf, V.A., Trebesius, K., Autenrieth, I.B., 2000. Fluorescent in situ hybridization allows rapid identification of microorganisms in blood cultures. J. Clin. Microbiol. 38, 830-838.

[10] Kim, J.Y., Kim, S.H., Kwon, N.H., Bae, W.K., Lim, J.Y., Koo, H.C., Kim, J.M., Noh, K.M., Jung, W. K., Park, K.T., Park ,Y.H., 2005. Isolation and identification of Escherchia coli $\mathrm{O} 157: \mathrm{H} 7$ using different detection methods and molecular determination by multiplex PCR and RAPD. J. Vet .Sci. 6, 7-19.

[11] Komiyama, M., Ye, S., Liang, X., Yamamoto, Y., Tomita, T., Zhou, J.M., Aburatani, H., 2003. PNA for one-base differentiating protection of DNA from nuclease and its use for SNPs detection. J. Am. Chem. Soc. 125, 3758-3762.

[12] Kwon, D., Kim, O., Chae, C., 1999. Prevalence of genotypes for firmbriae and enterotoxins and of $\mathrm{O}$ serogroups in Escherichia coli isolated from diarrheic piglets in Korea. J. Vet. Diagn. Invest. 11, 146-151.

[13] Nielsen, P.E., Egholm, M., Berg, R.H., Buchardt, O., 1991. Sequence-selective recognition of DNA by stand displacement with a thymine-substituted polyamide. Science. 254, 1497-1500.

[14] Nielsen, P.E., 1998. Structural and biological properties of peptide nucleic acid (PNA). Pure. Appl .Chem. 70, 105-110.

[15] Pellestor, F., Paulasova, P., 2004. The peptide nucleic acids, efficient tools for molecular diagnosis (Review). Int. J. Mol. Med. 13, 521-525.

[16] Quinones, B., Swimley, M.S., Taylor, A.W., Dawson, E.D., 2011. Identification of Escherchia coli O157 by using a novel colorimetric detection method with DNA microarrays. Foodborne. Pathog. Dis. 8, 705-711.

[17] Rangel, J.M., Sparling, P.H., Crowe, C., Griffin, P.M.,
Swerdlow, D.L., 2005. Epidemiology of Escherichia coli O157:H7 outbreaks, United states, 1982-2002. Emerg. Infect. Dis. 11, 603-609.

[18] Ratilainen, T., Holmén, A., Tuite, E., Nielsen, P.E., Norden, B., 2000. Thermodynamics of sequence-specific binding of PNA to DNA. Biochemistry. 39, 7781-7791.

[19] Riley, L.W., Remis, R.S., Helgerson, S.D., McGee, H.B., Wells, J.G., Davis, B.R., Hebert, R.J., Olcott, E.S., Johnson, L.M., Hargrett, N.T., Blake, P.A., Cohen, M.L., 1983. Hemorrhagic colitis associated with a rare Escherichia coli serotype. N. Engl. J. Med. 308, 681-685.

[20] Sheng, H., Lim, J.Y., Watkins, M.K., Minnich, S.A., Hovde, C.J., 2008. Characterization of an Escherichia coli $\mathrm{O} 157: \mathrm{H} 7$ O-antigen deletion mutant and effect of the deletion on bacterial persistence in the mouse intestine and colonization at the bovine terminal rectal mucosa. Appl. Environ. Microbiol. 74, 5015-5022.

[21] Stender, H., 2003. PNA FISH: an intelligent stain for rapid diagnosis of infectious diseases. Expert. Rev. Mol. Diagn. 3, 649-655.

[22] Velusamy, V., Arshak, K., Korostynska, O., Oliwa, K., Adley, C., 2010. An overview of foodborne pathogen detection : In the perspective of biosensors. Biotechnol. Adv. 28, 232-254.

[23] Wang, L., Reeves, P.R., 1998. Organization of Escherichia coli $\mathrm{O} 157 \mathrm{O}$ antigen gene cluster and identification of its specific genes. Infect. Immun. 66, 3545-3551.

[24] Weiler, J., Gausepohl, H., Hauser, N., Jensen, O.N., Hoheisel, J.D., 1997. Hybridisation based DNA screening on peptide nucleic acid (PNA) oligomer arrays. Nucleic. Acids. Res. 25, 2792-2799.

[25] Wells, J.S., Davis, B.R., Wachsmuth, I.K., Riley, L.W., Remis, R.S., Sokolow, R., Morris, G.K., 1983. Laboratory investigation of hemorrhagic colitis outbreaks associated with a rare Escherichia coli serotype. J. Clin. Microbiol. 18, $512-520$.

[26] Willshaw, G.A., Cheasty, T., Smith, H.R., O'Brien, S.J., Adak, G.K., 2001. Verocytotoxin-producing Escherichia coli (VTEC) O157 and other VTEC from human infections in England and Wales: 1995-1998. J. Med. Microbiol. 50, 135142.

[27] You, J.Y., Moon, B.M., Oh, I.G., Baek, B.K., Li, L.G., Kim, B.S., Stein, B.D., Lee, J.H., 2006. Antimicrobial resistance of Escherichia coli $\mathrm{O} 157$ from cattle in Korea. Int. J. Food. Microbiol. 106, 74-78. 